\title{
Randomised controlled trial of the effects of physical activity feedback on awareness and behaviour in UK adults: the FAB study protocol [ISRCTN92551397]
}

Clare Watkinson ${ }^{1}$, Esther MF van Sluijs ${ }^{1}$, Stephen Sutton ${ }^{2}$, Theresa Marteau ${ }^{3}$, Simon J Griffin ${ }^{1 *}$

\begin{abstract}
Background: While there are increasing data implicating poor recognition of physical inactivity as a potential barrier to healthy behaviour change, the efficacy of feedback to promote physical activity is uncertain. Using a randomised controlled trial nested within a population-based cohort study, we plan to test three variations of physical activity feedback against a control group. Our primary objective is to assess the efficacy of physical activity feedback in promoting physical activity behaviour change. Secondary objectives are to determine the influence of feedback on physical activity awareness and cognitions, and to compare behavioural effects by type of feedback.

Methods/Design: We aim to recruit 500 healthy participants aged 30 to 55 years from the ongoing Fenland Study (Cambridge, UK). Following careful phenotyping during baseline measurement (anthropometric, clinical, body composition and fitness measurements, as well as questionnaires assessing self-reported and self-rated physical activity, psychosocial correlates of physical activity behaviour, diet, lifestyle and general health), participants wear a combined heart rate and movement sensor (Actiheart ${ }^{\oplus}$ ) for six continuous days and nights. After receipt of the physical activity data (around 2 weeks later), participants are randomly allocated to either a control group (no feedback) or one of three types of personalised physical activity feedback ('simple', 'visualised' or 'contextualised'), and complete repeat measures of self-rated physical activity and psychosocial correlates. Approximately five weeks after receiving feedback, all participants wear the Actiheart ${ }^{\circledR}$ for another six-day follow-up period and complete repeat questionnaires. Values at outcome, adjusted for baseline, will be compared between randomised groups.

Discussion: Given the randomised trial design and use of objective measure of physical activity, this study is likely to provide valuable insights into the efficacy of a feedback intervention in changing physical activity behaviour, as well as the psychological mechanisms involved.
\end{abstract}

Trial Registration: Current Controlled Trials: ISRCTN92551397

\section{Background}

Low levels of physical activity have been associated with a variety of health problems, including mortality, cardiovascular disease, metabolic disorders and certain forms of cancer [1]. Two-thirds of UK adults do not meet government targets for physical activity [2] and effective strategies to promote active lifestyles are still lacking $[3,4]$. Even where interventions have had positive results,

\footnotetext{
* Correspondence: simon.griffin@mrc-epid.cam.ac.uk

${ }^{1}$ MRC Epidemiology Unit, Institute of Metabolic Science, Addenbrookes Hospital, Box 285, Hills Road, Cambridge, CB20QQ, UK
}

recent reviews show that effect sizes are generally small and short-lived [3]. It is unclear whether the absence of anticipated outcomes in intervention studies is due to failure to target key determinants and mediators, inadequate execution of an intervention or inexact measurement of the outcome [3].

One possibility is that sedentary individuals do not perceive themselves as such, incorrectly believing themselves to be active. Unlike dichotomous behaviours such as smoking, physical activity is complex, spanning multiple planned, incidental and habitual activities over a

\section{(Ciomed Central}


24-hour period. Consequently, thresholds of sufficient and insufficient activity may be unclear [5]. Evidence to date suggests that up to $60 \%$ of adults who do not currently meet the recommended guidelines for physical activity overestimate their own level [6]. Moreover, only $27 \%$ report a positive intention to change behaviour, compared to $43 \%$ among those who accurately assess their inactivity [6]. Despite being at greatest risk of health problems, those who fail to recognise their inactivity are unlikely to perceive a need to change and may be less susceptible to health promotion strategies.

Studies on the correlates of misperceptions about health behaviours suggest correlations with anthropometric characteristics and styles of interpersonal comparisons. People who erroneously classify themselves as adequately active are more likely to compare themselves with those perceived to engage in the same or lower levels (downward comparison) for example, and to rate their own behaviour as healthier (optimistic bias) [7,8]. Studies also show that overestimation is associated with favourable indicators of health. Those with a lower body mass index (BMI) or body fat \%, or with a more positive general perception of their health, more often assume that their physical activity is sufficient or high $[5,6,9]$. Such findings could help identify and target individuals at risk of such misperceptions.

Physical activity awareness (defined as the agreement between self-rated and actual activity level according to current guidelines) has rarely been studied as a determinant of healthy behaviour change. The Precaution Adoption Process Model identifies awareness of personal risk behaviour as an important step toward behaviour change, and posits that people are only expected to consider changing their behaviour when they become aware that they personally engage in too little physical activity and are potentially putting their health at risk [10]. Measurement and feedback may help to achieve this and have been shown to increase both awareness of health behaviour and intentions to change that behaviour $[11,12]$. Along similar lines, self-regulation theories consider self monitoring (a particular type of measurement and feedback) to be an essential element of behavioural self-regulation $[13,14]$. Indeed, a recent review of studies including pedometer interventions demonstrated consistent associations between the use of pedometers and increased physical activity [15].

Little is known about the effects of external feedback on physical activity awareness, intentions and behaviour, and even less about the efficacy of different types of feedback [16]. Of the evidence that is available, the majority comes from risk communication research and hypothetical vignette studies where the effects of feedback are primarily evaluated on the ability to influence perceptions of risk or intentions to change behaviour. For example, studies in tanning booth users [17] and smokers [18] show that people receiving personalised visual images of their disease or risk (a photograph that highlighted UV damage on the face and an ultrasound image of atherosclerotic plaque build-up in their carotid artery, respectively) are more likely to change their behaviour than those provided with written or verbal feedback. In addition, research also highlights that individually tailored interventions are more likely to be read, saved, remembered and discussed [11,19,20] and that goal setting in combination with self-monitoring is more successful $[15,21,22]$. However, to our knowledge no study has objectively measured change in health behaviours. A recent empirical review identified only eight randomised trials that investigated the effects of 'biomarker' feedback (biological indices of physical harm, disease, or increased disease risk) on motivation and intention to change health-related behaviour, or behaviour change itself [23]. Of those identified, only one examined physical activity behaviour. While there was some indication that feedback may increase motivation to change behaviour, this was limited by a reliance on imprecise measures of behaviour [24].

Importantly, the potential negative effects of feedback have also not been adequately addressed [25]. Many people who undergo a physical assessment receive results that lie within the normal or recommended range. Little is known about the impact of these 'desirable' results on future health beliefs and behaviour. While some people may be motivated to maintain their current status, others may be falsely reassured, perceiving less need to engage in health-promoting behaviours [26,27]. Conversely, undesirable feedback may trigger denial, threat minimisation or fatalistic attitudes, impeding an active role in health behaviour change [28]. Of seven studies reporting on the impact of cholesterol screening in a recent systematic review, six reported negative consequences for acceptance of risk caused by receipt of a high-risk result [25].

The present study will be the first to combine a randomised controlled trial design, objective outcome assessment and population-based sample to explore the effects of feedback on physical activity awareness, intentions and behaviour. We draw on relevant theories to select psychological measures with evidence of predictive ability to enable us to identify possible moderators and mediators of behaviour change. We will test three feedback types: simple, visual or contextualised. Our main aim is to assess the influence of personalized and normative physical activity feedback on free-living physical activity physical activity awareness and cognitions by comparing outcomes in three intervention groups (collectively and individually) against a control group. Our secondary research questions are a) which cognitions mediate the intervention effect, and b) whether potential effect(s) differ by feedback type. 


\section{Methods/Design Design}

The Feedback, Awareness and Behaviour study (FAB) is a randomised controlled trial with randomisation of 500 participants of the Fenland Study to either no feedback (control group) or to 'Simple', 'Visual', or 'Contextualised' physical activity feedback (intervention groups).

\section{Recruitment \\ The Fenland Study}

The Fenland Study is an ongoing population-based cohort study investigating the influence of diet, lifestyle and genetic factors on the development of diabetes, obesity and other metabolic disorders http://www.mrc-epid. cam.ac.uk/Research/Studies/Fenland/index.html. Residents of Cambridgeshire (East of England, UK) aged 3055 years registered at participating general practices (GP) are eligible to take part. Potential participants are excluded from the Fenland study by their GP if they have been diagnosed with diabetes, have a terminal illness with a prognosis of less than one year, suffer from a psychotic illness, are pregnant or lactating, or are unable to walk unaided. Recruitment operates via a predefined sampling frame (a list of patients meeting the inclusion criteria provided by all participating GPs prior to commencement of the study), whereby potential participants are assigned a study ID number and contacted in a random order. GPs approach potential participants via letters enclosing an information sheet, reply slip and freepost reply envelope. Individuals who return positive replies are contacted by the study office to arrange an appointment for them to attend a measurement facility. Written confirmation of the appointment is sent two weeks before, the Fenland informed consent form is signed on the testing day. Currently, around 30\% of adults registered with participating general practices in the Cambridgeshire Primary Care Trust have agreed to take part.

\section{The FAB Study}

Between September 2007 and August 2008 all Fenland participants were invited to take part in the FAB Study via a letter and information sheet included in their appointment confirmation packs. These explain that we are looking for a small number of participants who would be willing, in addition to their standard visit, to complete some further measures. Full details are provided in the Information Sheet, along with a short summary of the aim ('to investigate the effects of the Fenland study experience on participants and to help us understand the best way of providing people with feedback on their health'). Those who agree to participate are asked to sign an additional consent form at the beginning of their testing day.

\section{Study flow/procedures Baseline}

Trial design and participant flows are shown in Figure 1. Immediately after giving informed consent (and prior to any Fenland testing) participants are asked to complete the FAB baseline questionnaire measures. On the testing day, Fenland participants undergo a range of anthropometric (e.g. height, weight, hip and waist circumference), clinical (e.g. blood pressure), body composition (e.g. body fat percentage and distribution using ultrasound and dual energy x-ray absorptiometry) and fitness measurements (heart rate (HR), movement and oxygen consumption at rest and during a sub-maximal treadmill test). They also complete questionnaires on diet, physical activity, medical history and general lifestyle. In addition, an oral glucose tolerance test is administered and two blood samples are taken to assess glucose levels and blood lipids. At the end of the appointment, which takes an average of 3 to 3.5 hours, participants are fitted with a combined movement sensor and HR monitor (Actiheart $^{\oplus}$, CamNtech, Cambridge, UK [29]). This is worn for six days and nights and returned to the measurement facility in a prepaid special delivery envelope.

\section{Randomisation}

Once the Actiheart ${ }^{\circledast}$ monitor has been successfully downloaded and all relevant baseline data are available, participants are randomly allocated to either the control group or one of three feedback groups. Randomisation is carried out using a statistical minimisation programme (overseen by a statistician) on the basis of age $(<45, \geq 45$ years), gender (male/female), baseline physical activity level (PAL), an expression of the ratio of total energy requirements to basal metabolic rate over a 24-hour period ( $<1.63, \geq 1.63)$, BMI $\left(<27, \geq 27 \mathrm{~kg} / \mathrm{m}^{2}\right)$ and glycosylated haemoglobin (Hba1c: $<5.4, \geq 5.4 \%$ ), and is carried out independently of those undertaking baseline and follow-up measurements at the testing sites. Minimisation cut-offs were derived from an analysis of mean and median values in the first 1000 Fenland participants measured. Participants for whom sufficient baseline physical activity data is not available (less than 3 full days or 35 hours in total) are excluded from the study. Current data from the Fenland study suggest that this applies to fewer than $10 \%$ of participants. Since the FAB study is a trial of the impact of feedback of information, it is not possible to conceal group allocation from participants.

\section{Mailout 1 (approximately 2 weeks after the testing day)}

After receipt of the physical activity data, all participants are sent the second FAB questionnaire and participants allocated to one of the feedback groups receive their personal physical activity feedback. They are asked to read through the feedback and check that they have 


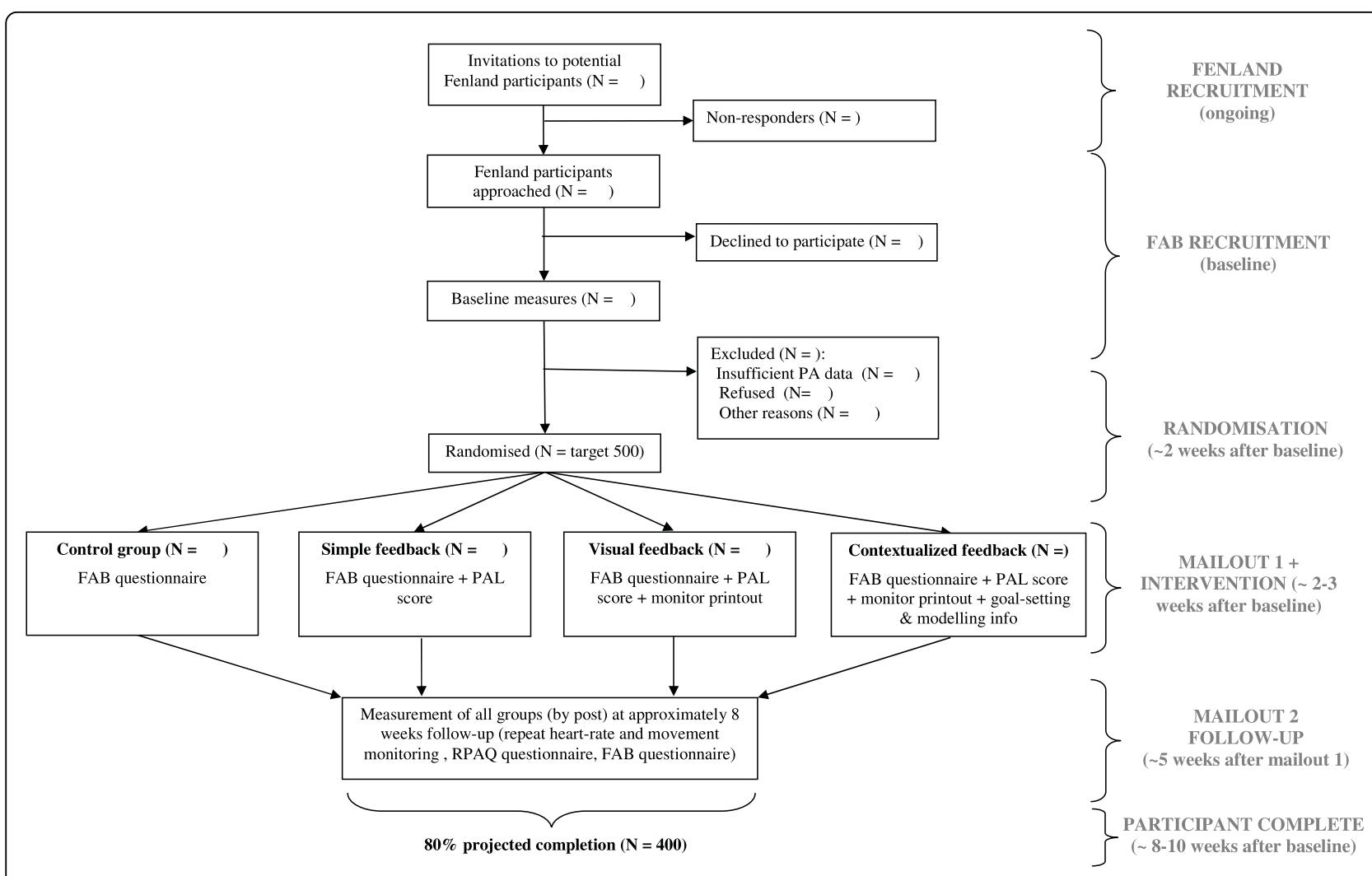

Figure 1 Flow of participants in FAB study

understood it before completing the questionnaire. All groups are asked to return their completed questionnaires by freepost envelope. A reminder letter, along with a second copy of the questionnaire, is sent if responses are not received within 2 weeks. The timing of Mailout 1 is dependent on the speed with which the first Actiheart ${ }^{\oplus}$ monitor is returned, but will usually occur around 2 weeks after baseline measurement.

\section{Mailout 2 (approximately five weeks after Mailout 1)}

Approximately five weeks after Mailout 1 is posted, participants are contacted by telephone to arrange sending out their second measurement pack (Mailout 2). This includes an Actiheart ${ }^{\circ}$ monitor, two questionnaires (FAB questionnaire and self-reported physical activity) and full instructions about how to attach the monitor correctly. They are asked to wear the monitor for another period of six days and nights and to return it with their completed questionnaires using the prepaid special delivery envelope provided. The purpose of the telephone call is to ensure that people will be able to wear the monitor in the near future. If this is not possible, a more convenient timing will be arranged.

We decided on a five-week (post-intervention) followup period to allow sufficient time for the dissipation of early novelty responses and thus detect behaviour change of a more sustained nature. Allowing one week for information to 'sink in', it also matches the reference period covered by physical activity questionnaire (one month). Mailout 1 is chosen as the baseline index point for calculating Mailout 2 posting dates in order to control the period of time between intervention and outcome measurement as much as possible. In total, we aim that participation in the $F A B$ study lasts for approximately 8-10 weeks from a participant's initial Fenland testing day to completion of follow-up, but this may vary between participants due to monitor re-wear and delays in sending out Mailout 2. Overall duration and stage-specific duration are recorded during the study in order to ensure equal average follow-up time between the groups.

\section{Intervention}

The content of each feedback type has been chosen to reflect promising approaches identified in the recent literature. To facilitate the isolation of effect estimates for individual feedback components, each feedback level is built on the previous one to create an ordered categorical variable based on simple feedback as its most basic level (see Figure 2).

\section{Simple Feedback}

Participants randomised to this group receive a short definition of physical activity; a summary of its health 


\section{\begin{tabular}{ll} 
PAL score $\quad$ Monitor output $\quad \begin{array}{c}\text { Goal setting \& } \\
\text { Modelling }\end{array}$ \\
\hline
\end{tabular}}

Control group

Simple

Visual

Contextualised

Figure 2 Distribution of feedback components across the four trial groups in the FAB study

benefits; and a brief reminder of current guidelines (see additional file 1, Appendix A). In addition, they are informed of their average PAL across the period during which they wore the Actiheart ${ }^{\bullet}$ monitor at baseline. This is calculated using Actiheart ${ }^{\circ}$ software, and is provided alongside a simple table showing the $\mathrm{FAO} / \mathrm{WHO} /$ UNU reference categories (Table 1) [30].

\section{Visual Feedback}

As mentioned previously, studies have indicated that people who are shown personalised visual images of their disease or risk are more likely to change their behaviour than those provided with written or verbal feedback. In one study, students shown a photograph that highlighted UV damage on their face reported less tanning booth use at follow-up than students not shown such a photograph, though both received verbal and written risk information [17]. Another study found that showing smokers an ultrasound image of atherosclerotic plaque build-up in their carotid artery, together with an image of a disease-free artery, increased perceptions of risk and intentions to stop smoking compared to those who received routine verbal feedback [18].

In the context of the Fenland study, the nearest approximation to 'visual imagery' is the output generated from the Actiheart ${ }^{\circ}$ software (see additional file 1, Appendix B). Participants randomised to 'Visual Feedback' receive a modified version of this output (consisting of a series of graphs on one side of A4), alongside their 'simple feedback'. Each graph represents a single day of measurement along a 24-hour $\mathrm{x}$-axis and plots a graphical record of the participant's HR and movement counts for each day they wore the sensor, briefly explained in their feedback sheet. We anticipate that this will allow participants to see how their HR and movement vary -or do not vary- at different times of the day or week, and to correlate specific activities they remember undertaking with corresponding peaks or troughs in the lines. Participants also receive example printouts of each PAL value described in the reference table, each one illustrating a HR and movement pattern typical of this PAL value.

\section{Contextualised Feedback}

Studies have indicated that goal setting is associated with more successful weight management $[21,22]$ and significant increases in daily pedometer counts [15], and that people who set personal goals tend to use positive behavioural strategies over negative ones [31,32]. On this basis, the third level of feedback ('Contextualised Feedback') aims to provide tailored goal setting and modelling information (see additional file 1, Appendix C). In addition to the 'simple' and 'visual' components, it includes estimates of the added PAL value of familiar activities (e.g. housework, walking or cycling) calculated for different durations (1 hour, 2 hours etc). It also incorporates a short fictional gender-specific vignette based on a 'typical' Fenland participant (aged 35-50), designed to address physical activity misperceptions and encourage behaviour change. Although the actual content was identical, 'Jenny' was used for the female version and 'John' for the male version to promote identification with the character.

The duration of each activity necessary to increase average daily PAL by 0.1 or 0.2 was calculated using the updated Compendium of Physical Activities [33]. Average daily resting energy expenditure (REE) was taken as equal to $1392 \mathrm{METmins} /$ day (REE $=1 \times 960$ METmins/ day $+0.9 \times 480=1392 \mathrm{METmins} /$ day $)$.

Table 1 Reference values for physical activity levels (PAL) as published by FAO/WHO/UNU [30]

\begin{tabular}{cl}
\hline PAL Value & Description \\
\hline Less than 1.2 & Bed rested: Most likely when in care of others \\
1.2 to 1.55 & Low activity level: Sedentary lifestyle. \\
1.55 to 1.71 & Medium activity level: Occasionally active. Typical office work. \\
1.71 to 1.95 & High activity level: Some manual work and/or regular exercise \\
Greater than 1.95 & Very high activity level: A fair amount of manual work or exercise training. \\
\hline
\end{tabular}




\section{Pilot testing}

Materials were pilot tested with twenty Fenland participants, who were asked to read through the example feedback a couple of times before taking part in a short structured interview. This aimed to explore their understanding, attitude, opinions and preferences in relation to the material presented, and minor revisions were made on the basis of the results. To address the confusion expressed by some participants about the main determinant of PAL (movement or HR), we included a brief explanation in all feedback types. We also clarified the connection between the participant's PAL result, the reference table and the example Actiheart ${ }^{\oplus}$ printouts in the visual feedback. Lastly, we removed unnecessary details from the Actiheart ${ }^{\ominus}$ graphs (e.g. HR and movement scales on the y-axis) and enlarged the image to facilitate comprehension.

\section{Measurements}

\section{Objectively-measured physical activity}

All trial measures and their timing are shown in Table 2. The main outcome measures are 1) physical activity energy expenditure per $\mathrm{kg}$ of fat free mass/minute (PAEE) and 2) total daily movement counts (DPA), measured via individually-calibrated $\mathrm{HR}$ and movement monitors (Actiheart ${ }^{\oplus}$ ) [29]. Participants are asked to wear the monitor for six days and nights continuously, and to carry on with all normal activities during this time. The Actiheart ${ }^{\oplus}$ is a non-invasive, single-piece combined monitor, which weighs less than $8 \mathrm{~g}$, is $7 \mathrm{~mm}$ thick (33 $\mathrm{mm}$ in diameter), waterproof and worn on the chest attached to standard ECG electrodes. It is capable of measuring acceleration, HR, HR variability, and ECG amplitude for a set time resolution. The monitor is convenient and discreet to wear, helping to reduce the potential Hawthorne effect (behavioural modification caused by the act of being observed) [34,35]. Participants are asked to complete an diary sheet, noting down the date and time they a) started wearing the monitor, b) removed it (along with the reason), and replaced it again, and c) completed measurement.

HR response to a sub-maximal exercise test is established during the testing day and is used for individual calibration of the Actiheart ${ }^{\circ}$ [36], and branched equation modelling is utilised to estimate PAEE [37]. This approach has high validity for estimating the intensity of physical activity [38] and overcomes some of the key limitations associated with either accelerometers or HR monitors alone [29].

Table 2 FAB trial measurements and their timing

\begin{tabular}{|c|c|c|c|}
\hline & $\begin{array}{c}\text { Baseline } \\
\text { visit }\end{array}$ & $\begin{array}{c}\text { Mailout } 1 \\
\text { ( 2 wks } \\
\text { post-baseline) }\end{array}$ & $\begin{array}{c}\text { Mailout } 2 \\
(\sim 5 \text { wks } \\
\text { post-Mailout 1) }\end{array}$ \\
\hline \multicolumn{4}{|l|}{ Main outcome } \\
\hline $\begin{array}{l}\text { 1. PA - 6-day HR and movement monitoring } \\
\text { (Actiheart }{ }^{\oplus} \text { ) }\end{array}$ & $\checkmark$ & & $\checkmark$ \\
\hline \multicolumn{4}{|l|}{ Other outcomes } \\
\hline 2. PA awareness & $\checkmark$ & & $\checkmark$ \\
\hline $\begin{array}{l}\text { 3. Fenland measures (anthropometry, body } \\
\text { composition, fitness) }\end{array}$ & $\checkmark$ & & \\
\hline 4. Self-reported PA & $\checkmark$ & & $\checkmark$ \\
\hline \multicolumn{4}{|l|}{ 5. Self-rated PA: } \\
\hline i. Absolute (WHO categories) & $\checkmark$ & $\checkmark$ & $\checkmark$ \\
\hline ii. Relative (peer comparison) & $\checkmark$ & $\checkmark$ & $\checkmark$ \\
\hline iii. According to guidelines (CMO) & $\checkmark$ & $\checkmark$ & $\checkmark$ \\
\hline 6. Confidence in self-rated $\mathrm{PA}^{\mathrm{a}}$ & $\checkmark$ & $\checkmark$ & $\checkmark$ \\
\hline 7. PA Subjective norms ${ }^{a}$ & $\checkmark$ & $\checkmark$ & $\checkmark$ \\
\hline 8. Worry/concern about $\mathrm{PA}^{\mathrm{a}}$ & $\checkmark$ & $\checkmark$ & $\checkmark$ \\
\hline $\begin{array}{l}\text { 9. Perceived behavioural } \\
\text { control/self efficacy }{ }^{\mathrm{a}}\end{array}$ & $\checkmark$ & $\checkmark$ & $\checkmark$ \\
\hline 10. Behavioural beliefs ${ }^{\mathrm{a}}$ & $\checkmark$ & $\checkmark$ & $\checkmark$ \\
\hline $\begin{array}{l}\text { 11. Perceived importance of physical } \\
\text { activity for health }{ }^{\mathrm{a}}\end{array}$ & $\checkmark$ & $\checkmark$ & $\checkmark$ \\
\hline 12. Intention to change $\mathrm{PA}^{\mathrm{a}}$ & $\checkmark$ & $\checkmark$ & \\
\hline $\begin{array}{l}\text { 13. Time orientation (concern } \\
\text { about current/futureconsequences) }^{\text {a }}\end{array}$ & $\checkmark$ & & \\
\hline
\end{tabular}

PA: Physical activity; WHO: World Health Organisation; CMO: Chief Medical Officer

${ }^{a}$ : included in $\mathrm{FAB}$ questionnaire 


\section{Questionnaire measures}

Self-reported physical activity is measured using the Recent Physical Activity Questionnaire (RPAQ). This quantifies physical activity in four domains (work, travel, recreation and domestic life) over the preceding month. A validation study using doubly labelled water as the golden standard has shown the RPAQ to be valid in ranking individuals according to their energy expenditure [39].

Self-rated physical activity is measured at all timepoints using three different reference standards: 'Absolute' (PAL categories defined by FAO/WHO/UNU [30]); 'Relative' (peer comparison); and 'Recommended' (according to CMO guidelines [40]) (see Table 3). A question to assess the participant's confidence in their answers to these three questions is also included: "Overall, how confident do you feel about your answers to questions 1 to 3?" (very/moderately/somewhat/not at all).

Physical activity awareness is defined as the agreement between 'recommended' self-rated activity and objectively-measured physical activity according to current guidelines [40]. The 'recommended' reference standard was considered most relevant to public health research as it is the primary reference point for most physical activity interventions and health promotion messages [40]. Objective physical activity is defined on the basis of average PAL. Participants are classified as either active (PAL $\geq 1.7$ ) or inactive (PAL $<1.7)$ [30,41]. Selfrated and objectively-measured physical activity levels are then grouped in a $2 \times 2$ table to create four awareness categories: 'Realistic Actives', 'Realistic Inactives', 'Overestimators' and 'Underestimators' [6] (Figure 3).

Cognitive predictors of physical activity hypothesized to be directly associated with behaviour change are measured at all three time points [42]. Questions were drawn from the previously validated ProActive study questionnaires, which were based on the Theory of Planned Behaviour [43], and amended where appropriate $[44,45]$. Items are measured on a Likert scale ranging from 1 (strongly disagree) to 5 (strongly agree), and cover perceived adequacy ('I do enough physical activity to stay healthy'), subjective norms ('Most people who are important to me would want me to be more physically active'), perceived behavioural control/self efficacy ('I am confident that I could be more physically active in the next two months, if I wanted to'), behavioural beliefs ('If I was more physically active in the next two months, it is likely that my fitness would improve/my appearance would improve/I would feel better/my health would improve'), perceived importance for health ('Physical activity is important for maintaining good health'), and intention to change ('I intend to be more physically active in the next two months'). Worry and concern about physical activity is measured via a separate 5point Likert response scale (not at all/rarely/sometimes/ often/almost all the time) using two items ('During the past two weeks, how often have you thought about your level of physical activity/how often have thoughts about your level of physical activity affected your mood?'). Given previously suggested associations with other health-related behaviours $[46,47]$, a validated 9-item time-orientation measure (concern about current/future consequences) [48] is also completed at baseline via a 5point scale ranging from 1 (very unlike me) to 5 (very like me).

Questionnaires were piloted over two weeks at the Fenland testing facility in Ely, where participants' experiences and reactions were recorded via a brief structured interview with a member of the FAB study team. A few minor changes to question wording were made on the basis of respondent feedback, but overall comprehension was high and questions were rated as clear and userfriendly.

\section{Data analyses}

Analyses will be undertaken on an intention-to-treat basis. The main experimental comparison is receipt of physical activity feedback (intervention) versus no feedback (control), with PAEE and DPA as the principal outcomes and self-reported physical activity, awareness and cognitions as secondary outcomes. Values at outcome, adjusted for baseline, will be compared between randomised groups. Gender, baseline physical activity and baseline awareness will be investigated as potential moderators of the intervention effect. In addition, we will conduct sensitivity analyses assuming a range of

Table 3 Description of the three types of self-rated physical activity measured in the FAB study.

\begin{tabular}{lll}
\hline Category & Reference standard & Question used (answer categories) \\
\hline Absolute & PAL categories defined by & $\begin{array}{l}\text { On average, which category do you believe best describes your general level of physical activity? } \\
\text { (Bed-rested/Low/Medium/High/Nery High). }\end{array}$ \\
\hline Relative & Peer comparison & $\begin{array}{l}\text { In your opinion, compared to other people of your age and sex, how physically active are you? } \\
\text { (Much less/A little less/About the same/A little more/Much more). }\end{array}$ \\
\hline Recommended & CMO guidelines [40] & $\begin{array}{l}\text { According to national recommendations people should be active at a moderate intensity (e.g. } \\
\text { brisk walking) for at least } 30 \text { minutes per day at least } 5 \text { days a week. Please indicate whether you } \\
\text { think you achieved this level of activity over the last month. (Yes/No). }\end{array}$ \\
\hline
\end{tabular}

PAL: Physical activity level; WHO: World Health Organisation; CMO: Chief Medical Officer 


\section{Self-rated physical activity}

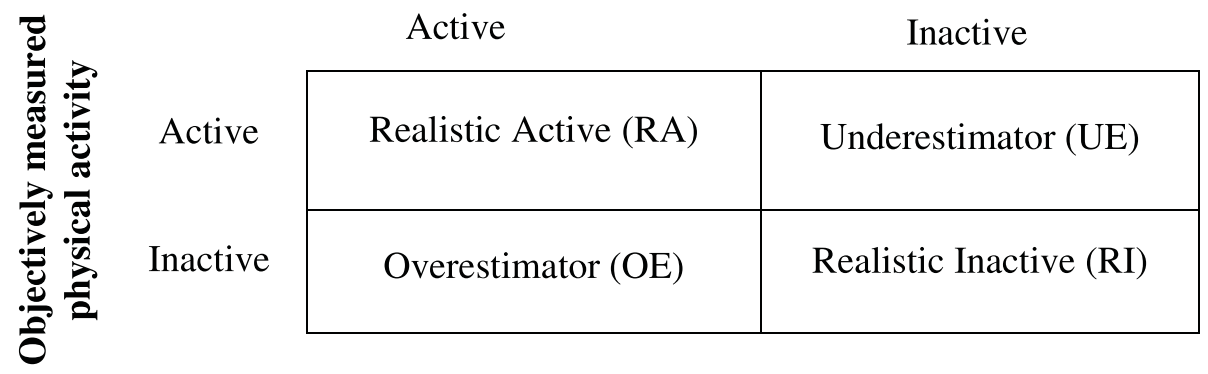

Figure 3 Method of classification of participants into awareness categories.

potential outcomes for non-completers informed by available baseline and interim data on this group. Noncompleters will have multiple data imputed with a 'missing at random' assumption and with sensitivity analyses to represent optimistic and pessimistic scenarios for drop out. To assess mediating effects, a product-of-coefficient test will be used [49]. A secondary dose-response analysis will compare each feedback type ('Simple', 'Visual' or 'Contextualised') with the control condition and with each other.

\section{Sample size}

Calculations were undertaken for a comparison between two equal-sized groups. Although the primary FAB analysis involves combining intervention groups and comparing them collectively against the control condition (intervention-control ratio $=3: 1$ ), secondary analyses compare each intervention group individually with the control group (intervention-control ratio $=1: 1$ ) and each other, and will therefore require additional power. Calculations are therefore based on the secondary analyses.

Estimates are taken from the ProActive trial [50], which used a comparable population, age-group and primary outcome to those proposed here. Participants mean (standard deviation, SD) PAEE at baseline in this study was $0.116(0.076) \mathrm{kJ} / \mathrm{kgFFM} / \mathrm{min}$. For a comparison between two groups, 100 participants per group completing follow-up would allow detection of a difference of $0.03 \mathrm{~kJ} / \mathrm{kgFFM} / \mathrm{min}$ in physical activity energy expenditure (which equates to approximately 225 to 300 Kcals, or roughly 20 mins brisk walking per day) with $80 \%$ power at the $5 \%$ significance level. However, by adjusting for baseline values we obtain greater precision. The correlation between baseline and follow-up PAEE in ProActive was 0.58 , meaning that 100 participants per group would allow detection of a difference of 0.025 $\mathrm{kJ} / \mathrm{kgFFM} / \mathrm{min}(0.33 \mathrm{SD})$. Thus we aim to randomise a total of 500 participants, with the expectation that 400 (80\%) would complete follow-up.

\section{Data management}

Each participant is assigned a unique numeric identifier code at the beginning of the Fenland study so that they can be tracked without reference to personal information and this will be continued to be used for the FAB study. As per usual Fenland procedures, all personal data is stored on an encrypted drive, and links to personal information are available only to the Fenland and FAB study coordination teams. Consent forms and questionnaire data are double-entered and stored in locked filing cabinets in secure Entacard-protected sites.

\section{Ethics}

Full ethical approval for the FAB study was obtained from the Cambridge Local Research Ethics Committee on $4^{\text {th }}$ June 2007 (reference number 07/Q0108/79). The study was registered under trial number ISRCTN92551397.

\section{Discussion}

There is increasing evidence that poor recognition of physical inactivity may be an important barrier to healthy behaviour change. Compelling observational data suggest that in terms of physical activity attitudes and intentions, people who incorrectly believe that their physical activity is adequate are comparable to those who achieve the recommended guidelines $[5,9,51]$ and thus resemble a group that public health interventions may not be able to reach. The FAB trial is designed to explore the effect of feedback on physical activity awareness, cognitions and behaviour in a population-based sample. In addition to estimating efficacy, it will provide information on possible psychological mechanisms of behaviour change. FAB has the potential to establish the extent to which increasing the accuracy of peoples' self-perceptions of physical activity might facilitate healthy behaviour change. However, it will also allow for the assessment of the risk for false-reassurance.

Our trial has been designed to address the limitations of previous work in the area of physical activity 
awareness and feedback. The use of a combined HR and movement sensor to asses physical activity overcomes the limitations associated with self-reported physical activity behaviour or intentions and is more accurate than either HR monitoring or accelerometry alone [29]. By drawing on relevant theory and evidence, we have chosen covariates with evidence of predictive ability for measurement at baseline and follow-up. These are expected to facilitate identification of possible moderators and mediators of behaviour change.

FAB is the first randomised trial of the effects of measurement and feedback on physical activity awareness, cognitions and behaviour using an objective measure of behaviour change and a population-based sample. Findings will be relevant to future studies that try to explain and change health behaviours in general and those on misperceptions about health behaviours in particular. Overall, it is expected that this will help inform the design of future preventive programmes promoting physical activity.

Additional file 1: Examples of the FAB feedback. Examples of the three types of physical activity feedback provided in the FAB study: Simple (Appendix A), Visual (Appendix B), and Contextualised (Appendix C).

\section{Acknowledgements}

This trial is funded by a Department of Health NIHR Programme Grant [RPPG-0606-1259], with additional support from the Medical Research Council (MRC) and the InterAct grant. The views expressed in this publication are those of the authors and not necessarily those of the Department of Health. InterAct is part-funded by the European Union (Integrated Project LSHM-CT2006-037197 in the Framework Programme 6 of the European Community). The trial was carried out by the MRC Epidemiology Unit in Cambridge, UK. We would like to thank the Field Epidemiology and Study Support teams for all their hard work recruiting participants and supporting the day-to-day running of the study. We are also grateful to Rachel Crockett for permission to use the Time Orientation measure, and would like to extend special thanks to Joanna Mitchell for all her valuable help and support coordinating the study. The final thank you goes to our participants: without their enthusiasm, commitment and willingness to help, we would not have a study.

\section{Author details \\ ${ }^{1}$ MRC Epidemiology Unit, Institute of Metabolic Science, Addenbrookes Hospital, Box 285, Hills Road, Cambridge, CB20QQ, UK. ${ }^{2}$ General Practice \& Primary Care Research Unit, Institute of Public Health, Forvie Site, Robinson Way, Cambridge, CB2 OSR, UK. 'King's College London, Psychology \& Genetics Research Group, Institute of Psychiatry, 5th Floor Thomas Guy House, Guy's Campus, London, SE1 9RT, UK.}

\section{Authors' contributions}

SG, EvS and CW defined the research question. All authors participated in the design of the trial, feedback intervention and measures. CW drafted the manuscript; all authors were involved in critical revisions and have read and approved the final manuscript.

\section{Competing interests}

The authors declare that they have no competing interests.

Received: 23 February 2010 Accepted: 18 March 2010

Published: 18 March 2010

\section{References}

1. Physical activity guidelines advisory committee report. [http://www health.gov/paguidelines/Report/Default.aspx]

2. Craig R, Mindell J: Health Survey for England 2006: CVD and risk factors adults, obesity and risk factors children. London, The NHS Information Centre 2008.

3. Hillsdon M, Foster C, Cavill N, Crombie H, Naidoo B: The effectiveness of public health interventions for increasing physical activity among adults: a review of reviews. London, Health Development Agency 2005.

4. van Sluijs EM, van Poppel MN, van Mechelen W: Stage-based lifestyle interventions in primary care: are they effective? Am J Prev Med 2004, 26(4):330-343

5. Ronda G, Van Assema P, Brug J: Stages of change, psychological factors and awareness of physical activity levels in the Netherlands. Health Promot Int 2001, 16(4):305-314

6. van Sluiis EM, Griffin SJ, van Poppel MN: A cross-sectional study of awareness of physical activity: associations with personal, behavioral and psychosocial factors. International Journal of Behavioral Nutrition and Physical Activity 2007, 4:53.

7. Brug J, Van Assema P, Kok GJ: Misconceptie van consumptie van vet, groente en fruit: Oorzaken en implicaties voor voedingsvoorlichting [Misperceptions of fat, fruit and vegetable consumption: causes and implications for dietary health education]. TSG 1998, 1:17-23.

8. Lechner L, Bolman C, Van Dijke M: Factors related to misperception of physical activity in The Netherlands and implications for health promotion programmes. Health Promot Int 2006, 21(2):104-112.

9. De Ridder $C$, Lechner $L$ : Overschatting van het eigen bewegingsgedrag: gevolgen voor determinanten en stages of change [Overestimation of physical activity behaviour: consequences for determinants and stages of change]. TSG 2004, 5:290-298.

10. Weinstein ND, Rothman AJ, Sutton SR: Stage theories of health behavior: conceptual and methodological issues. Health Psychol 1998, 17(3):290-299.

11. Brug J, Campbell M, van Assema P: The application and impact of computer-generated personalized nutrition education: a review of the literature. Patient Educ Couns 1999, 36(2):145-156.

12. Proper Kl, Beek van der AJ, Hildebrandt VH, Twisk JW, van Mechelen W: Short term effect of feedback on fitness and health measurements on self reported appraisal of the stage of change. Br J Sports Med 2003, 37(6):529-534

13. Kanfer FH, Karoly P: Self-control: a behavioristic excursion into the lion's den. Behav Ther 1972, 3:398-416.

14. Kirschenbaum DS: Self-regulatory failure: A review with clinical implications. Clinical Psychology Review 1987, 7(1):77-104.

15. Bravata DM, Smith-Spangler C, Sundaram V, Gienger AL, Lin N, Lewis $R$, Stave CD, Olkin I, Sirard JR: Using Pedometers to Increase Physical Activity and Improve Health: A Systematic Review. JAMA 2007, 298(19):2296-2304.

16. DiClemente CC, Marinilli AS, Singh M, Bellino LE: The Role of Feedback in the Process of Health Behavior Change. American Journal of Health Behavior 2001, 25(3)

17. Gibbons FX, Gerrard M, Lane DJ, Mahler HI, Kulik JA: Using UV photography to reduce use of tanning booths: a test of cognitive mediation. Health Psychol 2005, 24(4):358-363.

18. Shahab L, Hall S, Marteau TM: The motivational impact of showing smokers with vascular disease images of their arteries: a pilot study. British Journal of Health Psychology 2007, 12:275-83.

19. Skinner CS, Campbell MK, Rimer BK, Curry S, Prochaska JO: How effective is tailored print communication? Ann Behav Med 1999, 21(4):290-298.

20. Smeets T, Brug J, de Vries H: Effects of tailoring health messages on physical activity. Health Educ Res 2008, 23(3):402-413.

21. Kruger J, Blanck HM, Gillespie C: Dietary and physical activity behaviors among adults successful at weight loss maintenance. Int J Behav Nutr Phys Act 2006, 3(1):17.

22. Nothwehr F, Yang J: Goal setting frequency and the use of behaviora strategies related to diet and physical activity. Health Educ Res 2007, 22(4):532-538.

23. McClure JB: Are biomarkers useful treatment aids for promoting health behavior change? An empirical review. Am J Prev Med 2002, 22(3):200-207.

24. Gemson DH, Sloan RP, Messeri P, Goldberg IJ: A public health model for cardiovascular risk reduction. Impact of cholesterol screening with brief nonphysician counseling. Arch Intern Med 1990, 150(5):985-989. 
25. Bankhead CR, Brett J, Bukach C, Webster P, Stewart-Brown S, Munafo M, Austoker J: The impact of screening on future health-promoting behaviours and health beliefs: a systematic review. Health Technol Assess 2003, 7(42):1-92

26. Tymstra T, Bieleman B: The psychosocial impact of mass screening for cardiovascular risk factors. Fam Pract 1987, 4(4):287-290.

27. Kinlay S, Heller RF: Effectiveness and hazards of case finding for a high cholesterol concentration. Bmj 1990, 300(6739):1545-1547.

28. Clarke V, Crotty P, Pearson A: The Lay Epidemiological Perspective in Cholesterol Testing: Implications for Health Promotion. Social Sciences in Health: The International Journal of Research \& Practice 1997, 3:213-221.

29. Brage S, Brage N, Franks PW, Ekelund U, Wareham NJ: Reliability and validity of the combined $\mathrm{HR}$ and movement sensor Actiheart. Eur J Clin Nutr 2005, 59(4):561-570

30. FAO/WHO/UNU: Energy and Protein Requirements. Report of a Joint Expert Consultation. World Health Organization Technical Report Series No 724 Geneva: WHO 1985.

31. Estabrooks PA, Nelson CC, Xu S, King D, Bayliss EA, Gaglio B, Nutting PA, Glasgow RE: The Frequency and Behavioral Outcomes of Goal Choices in the Self-management of Diabetes. The Diabetes Educator 2005, 31(3):391-400.

32. Kruger J, Galuska DA, Serdula MK, Jones DA: Attempting to lose weight: Specific practices among U.S. adults. American Journal of Preventive Medicine 2004, 26(5):402-406.

33. Ainsworth B, Haskell W, Whitt M, Irwin M, Swartz A, Strath S, O'Brien W, Bassett D, Schmitz K, Emplaincourt P: Compendium of physical activities: an update of activity codes and MET intensities. Medicine \& Science in Sports \& Exercise 2000, 32:\$498-504.

34. Tate DF, Jackvony EH, Wing RR: Effects of Internet behavioral counseling on weight loss in adults at risk for type 2 diabetes: a randomized trial. Jama 2003, 289:1833-1836.

35. Wickstrom G, Bendix T: The 'Hawthorne effect'- what did the original Hawthorne studies actually show? Scand J Work Environ Health 2000, 26:363-367.

36. Brage S, Ekelund U, Brage N, Hennings MA, Froberg K, Franks PW, Wareham NJ: Hierarchy of individual calibration levels for HR and accelerometry to measure physical activity. J Appl Physiol 2007, 103(2):682-692.

37. Brage S, Brage N, Franks PW, Ekelund U, Wong MY, Andersen LB, Froberg K, Wareham NJ: Branched equation modeling of simultaneous accelerometry and HR monitoring improves estimate of directly measured physical activity energy expenditure. J Appl Physiol 2004, 96:343-351.

38. Strath SJ, Brage S, Ekelund U: Integration of physiological and accelerometer data to improve physical activity assessment. Med Sci Sports Exerc 2005, 37(11 Suppl):S563-571.

39. Besson H, Brage S, Jakes RW, Ekelund U, Wareham NJ: Estimating physical activity energy expenditure, sedentary time, and physical activity intensity by self-report in adults. The American journal of clinical nutrition 2010, 91(1):106-114.

40. Department of Health: At least five a week: Evidence on the impact of physical activity and its relationship to health. A report from the Chief Medical Officer. London 2004.

41. Saris W, Blair S, van Baak M, Eaton S, Davies P, Di Pietro L, Fogelholm M, Rissanen A, Schoeller D, Swinburn B: How much physical activity is enough to prevent unhealthy weight gain? Outcome of the IASO 1st Stock Conference and consensus statement. Obesity Reviews 2003, 4:101-114.

42. Hardeman W, Sutton S, Griffin S, Johnston M, White A, Wareham NJ, Kinmonth AL: A causal modelling approach to the development of theory-based behaviour change programmes for trial evaluation. Health Educ Res 2005, 20(6):676-687.

43. Azjen I: The theory of planned behaviour. Organizational Behavior and Human Decision Processes 1991, 50:179-211.

44. Williams K, Prevost AT, Griffin S, Hardeman W, Hollingworth W, Spiegelhalter D, Sutton S, Ekelund U, Wareham N, Kinmonth AL: The ProActive trial protocol - a randomised controlled trial of the efficacy of a family-based, domiciliary intervention programme to increase physical activity among individuals at high risk of diabetes [ISRCTN61323766]. BMC Public Health 2004, 4(1):48.
45. Sutton S, French D, Hennings SJ, Mitchell J, Wareham NJ, Griffin S, Hardeman W, Kinmonth AL: Eliciting salient beliefs in research on the Theory of Planned Behaviour: The effect of question wording. Current Psychology 2003, 22(3):234-251.

46. Luszczynska A, Gibbons FX, Piko BF, Tekozel M: Self-regulatory cognitions, social comparison, and perceived peers' behaviors as predictors of nutrition and physical activity: A comparison among adolescents in Hungary, Poland, Turkey, and USA. Psychology \& Health 2004, 19(5):577-593.

47. Rothspan S, Read SJ: Present versus future time perspective and HIV risk among heterosexual college students. Health Psychology 1996, 15(4):131-134

48. Crockett RA, Weinman J, Hankins M, Marteau T: Time orientation and health-related behaviour: Measurement in general population samples. Psychology \& Health 2009, 24(3):333-350

49. Krull JL, MacKinnon DP: Multilevel Modeling of Individual and Group Level Mediated Effects. Multivariate Behavioral Research 2001, 36(2):249-277.

50. Kinmonth A-L, Wareham NJ, Hardeman W, Sutton S, Prevost AT, Fanshawe T, Williams KM, Ekelund U, Spiegelhalter D, Griffin SJ: Efficacy of a theory-based behavioural intervention to increase physical activity in an at-risk group in primary care (ProActive UK): a randomised trial. The Lancet 2008, 371(9606):41-48.

51. Smeets T: Towards a healthy lifestyle: the development and evaluation of a computered tailored lifestyle intervention. PhD thesis. Maastricht University, Faculty of Health Sciences 2006.

\section{Pre-publication history}

The pre-publication history for this paper can be accessed here: [http://www.biomedcentral.com/1471-2458/10/144/prepub]

doi:10.1186/1471-2458-10-144

Cite this article as: Watkinson et al:: Randomised controlled trial of the effects of physical activity feedback on awareness and behaviour in UK adults: the FAB study protocol [ISRCTN92551397]. BMC Public Health 2010 10:144.

\section{Submit your next manuscript to BioMed Central and take full advantage of:}

- Convenient online submission

- Thorough peer review

- No space constraints or color figure charges

- Immediate publication on acceptance

- Inclusion in PubMed, CAS, Scopus and Google Scholar

- Research which is freely available for redistribution

Submit your manuscript at www.biomedcentral.com/submit
C Biomed Central 